УДК 336.025

\title{
В. В. Рощупкина
}

ФГАОУ ВО «Северо-Кавказский федеральный университет», Ставрополь, e-mail: kluvil@rambler.ru

\section{ЗЕМЕЛЬНЫЙ НАЛОГ ДЛЯ ПРЕДПРИНИМАТЕЛЕЙ - ЧТО НОВОГО? (НА МАТЕРИАЛАХ СТАВРОПОЛЬСКОГО КРАЯ)}

Ключевые слова: предприниматель, бизнес, социальный, бизнес-модель.

Земельное законодательство Российской Федерации (Земельный кодекс Российской Федерации и изданные в соответствии с ним иные акты) основывается на принципе платности использования земли. Любое использование земли осуществляется за плату. Экономический интерес органов местного самоуправления распространяется на определение налоговой базы по земельному налогу, так как указанные налоги в полном объеме зачисляются в местные бюджеты.

В Ставропольском крае размер налоговых ставок по земельному налогу установлен представительными органами муниципальных образований в размере предельных, базовых ставок, предусмотренных Налоговым кодексом. Согласно нормам, установленным Налоговым кодексом, льготами по налогам признаются предоставляемые отдельным категориям налогоплательщиков преимущества по сравнению с другими налогоплательщиками, включая возможность не уплачивать налог либо уплачивать их в меньшем размере.

\section{V. Roshchupkina}

North-Caucasian Federal University, Stavropol, e-mail: kluvil@rambler.ru

\section{LAND TAX FOR ENTREPRENEURS - WHAT'S NEW? (ON MATERIALS OF THE STAVROPOL TERRITORY)}

Keywords: entrepreneur, business, social, business model.

The land legislation of the Russian Federation (the Land Code of the Russian Federation and other acts issued in accordance with it) is based on the principle of payment for the use of land. Any land use is charged. The economic interest of local governments extends to determining the tax base for land tax, since these taxes are fully credited to local budgets.

In the Stavropol Territory, the tax rate for land tax is set by the representative bodies of municipalities in the amount of marginal, base rates provided by the Tax Code. According to the norms established by the Tax Code, tax benefits are granted to certain categories of taxpayers of advantages over other taxpayers, including the possibility not to pay tax or pay them in a smaller amount.

\section{Введение}

В соответствии с нормами, регулирующими порядок исчисления земельного налога, индивидуальный предприниматель, начиная с налогового периода 2015 года, не осуществляет самостоятельный расчет этого налога. За него это делает налоговый орган. Таким образом, индивидуальный предприниматель в части налога на землю приравнен к физлицам и должен платить его на основании уведомления, присланного Инпекцией федеральной налоговой службы, в срок, установленный для уплаты налога физлицами.

\section{Цель исследования}

Целью исследования является мониторинг законодательных инноваций по земельному налогу, регулирующих процесс налогообложения земельных участков на примере муниципальных образований Ставропольского края, в том числе, для предпринимателей.

\section{Материалы и методы исследования}

Российским Налоговым кодексом предпринимателям вменяется обязанность вносить платежина земельные участки. Она возникает, если соответствующее имущество принадлежит бизнесмену на основании прав собственности, наследования, а также бессрочного использования.

В соответствии с общим правилом предприниматель выступает плательщиком земельного налога при одновременном соблюдении двух условий:

- право собственности закреплено за бизнесменом документально; 
- земельный участок расположен на территории субъекта Российской Федерации, в котором действует соответствующий налог.

Если по каким-либо причинам у индивидуальных предпринимателей отсутствуют документы, подтверждающие право собственности, возможны две ситуации:

У предпринимателя не возникает обязанности платить соответствующие отчисления, если участок был куплен после 31 января 1998 года, но право на него не было оформлено. Важно помнить, что умышленное уклонение от государственной регистрации земли для снижения налогов грозит предпринимателю штрафом. Сумма его будет немалая и составит до $40 \%$ размера неустойки по налогу.

Если земельный участок был приобретён до 31 января 1998 года, индивидуальный предприниматель обязан оплачивать земельный налог даже при отсутствии бумаг на право собственности. Это объясняется тем, что в этой ситуации допускается подтверждение владения другими документами, например, соглашением купли-продажи.

Количество собственников земельных участков, землепользователей и землевладельцев, т. е. количество налогоплательщиков оказывает прямое влияние на размер налоговой базы. Чем больше зарегистрировано прав, тем больше налогооблагаемая база.

В данном случае у муниципалитетов имеется налоговый потенциал, заключающийся в вовлечении в налоговый оборот земельных участков, права на которые отсутствуют в Едином государственном реестре недвижимости, но существуют на основании государственных актов, свидетельств и других документов, удостоверяющих права на землю и выданных физическим или юридическим лицам до вступления в силу Федерального закона от 21.07.1997 № 122-Ф3 «О государственной регистрации прав на недвижимое имущество и сделок с ним». Указанные права имеют равную юридическую силу с записями в Едином государственном реестре прав на недвижимое имущество, но они не участвуют (выпадают) в межведомственном обмене, в целях учета и постановки на налоговый учет для налогообложения, сведениями об объектах недвижимости и их правообладателями между органами Росреестра и налоговыми органами. Таким образом, муниципалитеты должны пробуждать «добрую волю» физических подать заявление на регистрацию прав на земельные участки [1].

Муниципалитеты в целях недопущения необоснованного снижения налоговой базы - кадастровой стоимости, используемой для исчисления земельного налога, по решению комиссии о пересмотре результатов определения кадастровой стоимости, могут и должны принимать участие в процедуре рассмотрения установления кадастровой стоимости равной рыночной. При необходимости осуществлять оспаривание результатов [10].

Одним из направлений повышения налогового потенциала муниципального образования может послужить расширение списка объектов торговых центров (комплексов) общей площадью свыше 250 квадратных метров, принадлежащих физическим лицам, для включения их министерством имущественных отношений Ставропольского края в перечень объектов, в отношении которых налоговая база определяется как кадастровая стоимость. Экономическая составляющая местных бюджетов в данном случае выражается в разнице сумм налога, исчисленного по ставке $0,3 \%$ (для не включенных в перечень) и по ставке, установленной в отношении объектов налогообложения, включенных в перечень, которая в 2015 году установлена в размере $0,9 \%$, в 2016 году в размере $1,5 \%$, в 2017 году - в размере $1,5 \%$, в 2018 году - в размере $2 \%$ [2].

При этом не применяются коэффициенты, установленные для переходного периода применения кадастровой стоимости $(0,2$ для 2016 года, 0,4 для 2017 года, 0,6 для 2018 года и условия применения 1,1 для следующего года).

В отношении объектов, включенных в рассматриваемый перечень, не применяются условия освобождения по уплате налога индивидуальных предпринимателей, применяющих упрощенную систему налогообложения, и индивидуальных предпринимателей уплачивающих единый налог на вмененный доход для отдельных видов деятельности. Тогда, как по объектам, не включенным в перечень, индивидуальные предприниматели, применяющие упрощенную систему налогообложения (в отношении имущества, используемого для предпринимательской 
деятельности), и индивидуальные предприниматели, уплачивающие единый налог на вмененный доход для отдельных видов деятельности (в отношении имущества, используемого для осуществления предпринимательской деятельности, облагаемой единым налогом), предусматривает их освобождение от обязанности по уплате [3].

Еще одним направлением деятельности органов местного самоуправления является наполняемость и поддержание в актуальном состоянии сведений об объектах адресации, содержащихся в Государственном адресном реестре. Почтовый адрес объекта недвижимости (включая земельные участки) и/или места жительства/ места нахождения налогоплательщика является одним из элементов, используемых налоговыми органами для идентификации и постановки на налоговый учет объектов налогообложения и налогоплательщиков. Учитывая обязанность налоговых органов, исчислить физическим лицам земельный налог и налог на имущество физических лиц, предъявить их к уплате и направить налогоплательщику налоговое уведомление, в том числе по почте заказным письмом по адресу места жительства гражданина, наличие адреса обязательно, следовательно, если почтовый адрес будет неактуальным, либо сведения о нем будут отсутствовать в Государственном адресном реестре (ГАР), Почта России не сможет осуществить доставку федеральной налоговой корреспонденции (налоговые уведомления, требования и т.п.), в том числе и налогоплательщикам - физическим лицам [4].
Обязанность по размещению, изменению и аннулированию сведений об адресах в Государственном адресном реестре возложена Федеральным законом от 28.12.2013 №443-Ф3 на органы местного самоуправления. Согласно названному федеральному закону ответственность за достоверность, полноту и актуальность содержащихся в ГАР сведений об адресах несет орган местного самоуправления, разместивший такие сведения. Сведения об адресах, содержащиеся в ГАР, обязательны для использования органами государственной власти, органами местного самоуправления (при предоставлении государственных и муниципальных услуг), а также для использования при оказании услуг почтовой связи.

Земельный фонд Ставропольского края составляет 6,6 млн га, из которых:

- 92,4\% (6111,1 тыс. га) земель относятся к землям сельхоз назначения;

- 3,7\% (243,7 тыс. га) земли населенных пунктов;

- 0,8\% (53,4 тыс. га) земли промышленности, энергетики, транспорта, связи, радиовещания, телевидения, информатики, земли для обеспечения космической деятельности, земли обороны, безопасности и земли иного специального назначения;

- 0,001\% (52 га) земли особо охраняемых территорий и объектов;

- 1,7\% (114,1 тыс. га) земли лесного фонда;

- 0,8\% (55,6 тыс. га) земли водного фонда;

- 0,6\% (38 тыс. га) земли запаса [5].

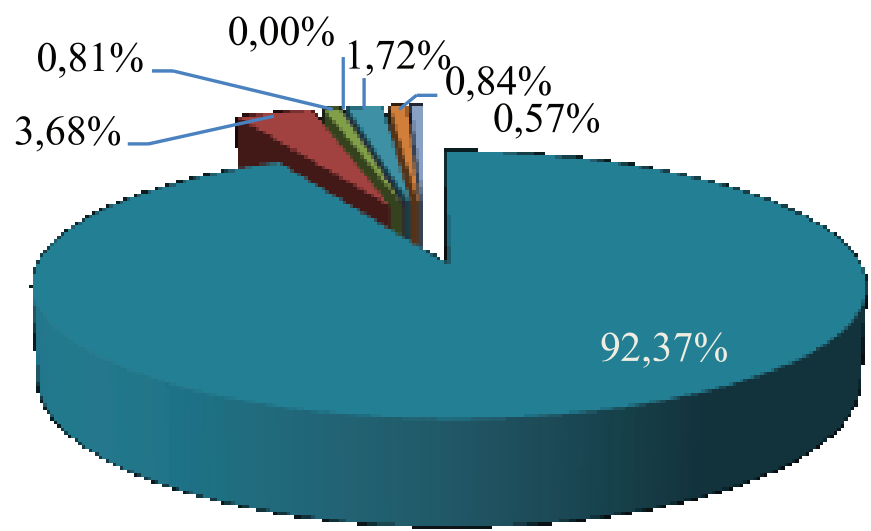

\author{
п земли сельхозназначения, \\ тыс. га \\ — земли населенных пунктов, \\ тыс. га \\ — земли промышленности, \\ энергетики, транспорта..., тыс. га \\ — земли особо охраняемых \\ территорий и объектов, тыс. га \\ ш земли лесного фонда, тыс. га \\ п земли водного фонда, тыс. га
}

Распределение земельного фонда Ставропольского края по категориям земель 
Таким образом, налоговый потенциал Ставропольского края составляет 96,9\% площади земельного фонда, в случае соблюдения условия - регистрация прав лицами (организации и физические лица) признаваемыми Налоговым кодексом налогоплательщиками на земельные участки, признаваемыми Налоговым кодексом, объектами налогообложения (на которые оформлены права собственности, постоянного (бессрочного) пользования или пожизненного наследуемого владения) [6].

При расчете прогноза поступлений по налогу темп роста на 2018 составил $94,3 \%$, на 2019 год принят в размере $100,0 \%$ (с учетом изменений внесенных Федеральным законом № 334-Ф3 от 03.08.2018 года).

Средняя ставка по земельному налогу с физических лиц за 2017 год составила $0,26 \%$ [7].

Расчётный уровень собираемости определен согласно данным отчёта по форме № 1-НМ за предыдущий год103,4\% (табл. 1).

При расчете прогнозного объема поступлений земельного налога с физических лиц учитываются выпадающие доходы в связи с предоставлением льгот, освобождений и пре- ференций, установленных в рамках главы 31 Налогового кодекса Российской Федерации, и других льгот, и преференций [8].

Расчет прогнозного объема поступлений земельного налога осуществляется методом прямого расчета с использованием показателей налоговой базы и налоговой ставки, и других показателей (уровень переходящих платежей, уровень собираемости).

Прогноз поступлений земельного налога с физических лиц осуществляется с учетом установленных сроков направления налоговыми органами налоговых уведомлений и уплаты налога в соответствии с Налоговым кодексом Российской Федерации.

При расчете прогноза поступлений по налогу темп роста на 2018 составил $96,8 \%$, на 2019 год принят в размере $100,0 \%$ (с учетом изменений внесенных Федеральным законом № 334-Ф3 от 03.08.2018 года).

Средняя ставка по земельному налогу с физических лиц за 2017 год составила $0,27 \%$.

Расчётный уровень собираемости определен согласно данным отчёта по форме № 1-НМ за 2017 год - 87,3\% (табл. 2).

Таблица 1

Расчет земельного налога с физических лиц по Ипатовскому городскому округу

\begin{tabular}{|l|c|c|c|c|}
\hline \multicolumn{1}{|c|}{ Наименование показателя } & & 2017 г. & 2018 г. & $\begin{array}{c}\text { Прогноз } \\
2019 \text { г. }\end{array}$ \\
\hline $\begin{array}{l}\text { Налоговая база в виде кадастровой стоимости зе- } \\
\text { мельных участков физических лиц }\end{array}$ & НБ & 14690557 & 13853195 & 13853195 \\
\hline $\begin{array}{l}\text { Коэффициент экстраполяции, рассчитываемый как } \\
\text { среднее арифметическое значение темпов роста } \\
\text { (снижения) налоговой базы в виде кадастровой сто- } \\
\text { имости к предыдущему периоду, \% }\end{array}$ & $K_{\text {экстр }}$ & $x$ & 94,3 & 100 \\
\hline $\begin{array}{l}\text { Расчетная средняя ставка по земельному налогу } \\
\text { с физических лиц за отчетный период, \% }\end{array}$ & $S$ & $x$ & 0,26 & 0,26 \\
\hline $\begin{array}{l}\text { Расчётный уровень собираемости, с учётом дина- } \\
\text { мики показателя собираемости по данному виду } \\
\text { налога, сложившегося в предшествующие периоды, } \\
\text { учитывает работу по погашению задолженности по } \\
\text { налогу, \% }\end{array}$ & $K_{\text {соб }}$ & $x$ & 103,4 & 103,4 \\
\hline $\begin{array}{l}\text { Корректирующая сумма поступлений, учитывающая } \\
\text { изменения законодательства о налогах и сборах, } \\
\text { а также другие факторы }\end{array}$ & $F$ & $x$ & 0 & 0 \\
\hline $\begin{array}{l}\text { Поступление налога } \\
\text { Прогнозируемый темп роста поступлений, \% }\end{array}$ & $3 \mathrm{H}_{\text {фл }}$ & 36827 & 37243 & 37243 \\
\hline
\end{tabular}


Таблица 2

Расчет земельного налога с физических лиц по Петровскому городскому округу

\begin{tabular}{|l|c|c|c|c|}
\hline \multicolumn{1}{|c|}{ Наименование показателя } & & 2017 г. & $\begin{array}{c}2018 \text { г., } \\
\text { ожидаемое }\end{array}$ & $\begin{array}{c}\text { Прогноз } \\
2019 \text { г. }\end{array}$ \\
\hline $\begin{array}{l}\text { Налоговая база в виде кадастровой стоимости земель- } \\
\text { ных участков физических лиц }\end{array}$ & НБ & 19802874 & 19169182 & 19169182 \\
\hline $\begin{array}{l}\text { Коэффициент экстраполяции, рассчитываемый как } \\
\text { среднее арифметическое значение темпов роста (сни- } \\
\text { жения) налоговой базы в виде кадастровой стоимости } \\
\text { к предыдущему периоду, \% }\end{array}$ & $K_{\text {эктр }}$ & $x$ & 96,8 & 100 \\
\hline $\begin{array}{l}\text { Расчетная средняя ставка по земельному налогу с фи- } \\
\text { зических лиц за отчетный период, } \%\end{array}$ & $S$ & $x$ & 0,27 & 0,27 \\
\hline $\begin{array}{l}\text { Расчётный уровень собираемости, с учётом динамики } \\
\text { показателя собираемости по данному виду налога, } \\
\text { сложившегося в предшествующие периоды, учитыва- } \\
\text { ет работу по погашению задолженности по налогу, \% }\end{array}$ & $K_{\text {соб }}$ & $x$ & 87,3 & 87,3 \\
\hline $\begin{array}{l}\text { Корректирующая сумма поступлений, учитывающая } \\
\text { изменения законодательства о налогах и сборах, а так- } \\
\text { же другие факторы }\end{array}$ & $F$ & $x$ & 0 & 0 \\
\hline Поступление налога & $3 \mathrm{H}_{\text {фл }}$ & 51545 & 45184 & 45184 \\
\hline Прогнозируемый темп роста поступлений, \% & & & 87,7 & 100,0 \\
\hline
\end{tabular}

При расчете прогнозного объема поступлений земельного налога с физических лиц учитываются выпадающие доходы в связи с предоставлением льгот, освобождений и преференций, установленных в рамках главы 31 Налогового кодекса Российской Федерации, и других льгот, и преференций.

Минфин России подготовил письмо от 3 апреля 2019 г. N 03-05-04-02/23083 «Об исчислении земельного налога в отношении земельных участков с видом разрешенного использования “Для индивидуального жилищного строительства", используемых в предпринимательской деятельности».

ФНС России обязало довести настоящие разъяснения до сотрудников налоговых органов, осуществляющих администрирование земельного налога, и организовать исполнение разъяснений, в т. ч. при формировании налоговых уведомлений (письмо № БС-4-21/6245@ от 05.04.2019 г.).

\section{Результаты исследования и их обсуждение}

Согласно ст. 388 Налогового кодекса Российской Федерации предприниматели обязаны уплатить земельный налог в бюджет, если земельный участок принадлежит им на основании одного из следующих прав:

- собственности;
- бессрочного использования;

- пожизненного наследования.

Кодекс в целях обложения земельным налогом не предъявляет требований и не устанавливает особенностей налогообложения в зависимости от наличия или отсутствия у физического лица статуса индивидуального предпринимателя.

При этом есть 3 группы условий, которые освобождают предпринимателей от уплаты налога [9].

В 1 группе содержатся обстоятельства, связанные с особенностью земельного участка, который:

- принадлежит к объектам лесного фонда;

- изъят из оборота в соответствии с законодательством Российской Федерации;

- ограничен в обороте и занят памятниками культуры или водными объектами из водного фонда;

- относится к общему имуществу многоквартирного фонда [10].

Во 2 группе рассматривается право, на основании которого предприниматель владеет участком:

- право безвозмездного пользования;

- передача по договору аренды.

3 группа - это характеристика самого предприниматели: если он относится к представителям коренного малочисленного населения Крайнего Севера, 
Сибири, Дальнего Востока (в отношении промысловых земель, территорий для проживания и хозяйствования) [11].

При наличии одного из перечисленных выше условий у предприниматели нет необходимости уплачивать налог на землю.

При оплате налога на землю в 2019 году предприниматели должны внимательно относиться к срокам. Нарушение даты оплаты приводит к начислению штрафов [12].

При самостоятельном оформлении документа на перечисление следует несколько раз проверить код бюджетной классификации.

Итогом вновь станет привлечение к ответственности.

Размер штрафных санкций зависит от условий их возникновения:

- Если индивидуальный предприниматель получил уведомление о необходимости оплатить земельный налог, но не сделал этого, неоплата считается умышленной. В этом случае размер штрафа устанавливается на уровне $40 \%$ от суммы земельного налога.

- Если платёж был внесён не полностью или не перечислен в силу экстренных ситуаций, штраф будет меньше. Он составит $20 \%$ от суммы налога [13].

Налоговые службы обычно вменяют неплательщику умышленную неуплату. То, что нарушение было допущено не специально, придётся доказывать в судебном порядке.

На основании вышесказанного Минфин России сделал вывод: исчисление земельного налога в отношении земельных участков с видом разрешенного использования «для индивидуального жилищного строительства», используемых в предпринимательской деятельности и предназначенных для дальнейшей перепродажи, осуществляется с учетом налоговой ставки, предусмотренной подпунктом 2 пункта 1 статьи 394 Кодекса [14].

То есть в отношении земельных участков «для индивидуального жилищного строительства», используемых в предпринимательской деятельности, применяется налоговая ставка, предусмотренная НК РФ для «прочих земельных участков» в размере, не превышающем $1,5 \%$, что в 5 раз выше ставки земельного налога, установленного в отношении земельных участков с видом разрешенного использования «для индивидуального жилищного строительства» $[15,16,17]$.

\section{Выводы (заключение)}

Земельный налог для индивидуальных предпринимателей в 2019 году подчиняется всем правилам, действующим для обычных физлиц, и платится на основании того же документа (уведомления ИФНС) и в те же сроки. Перенос срока уплаты земельного налога на 1 декабря года, наступающего за годом, за который оплачивается налог, - нововведение 2016 года. То есть, в 2019 году за 2018 год налог следует уплатить до 02.12.2019 (так как 1 декабря - воскресенье), а за 2019 год до 01.12.2020.

По новому закону с 2020 года приусадебные, садовые и огородные участки, которые используются для предпринимательской деятельности, будут облагаться земельным налогом по ставке для прочих земель, не превышающей 1,5\% от кадастровой стоимости.

Исследование выполнено при финансовой поддержке РФФИ в рамках научного проекта № 19-010-00017 A.

Библиографический список

1. Земельный налог для ИП в 2019 году [Электронный ресурс]. Режим доступа: https://nalognalog.ru/zemelnyj_nalog/zemelnyj nalog dlya ip/\#more.

2. Тищенко К.Э., Чушенко С.М. Особенности прогнозирования и планирования налоговых поступлений в Российской Федерации // Дневник наук. 2018. № 11.

3. Меркулов В.В., Русанов И.В., Русанова .А. Приоритеты совершенстования налоговой политики на региональном уровне // Актуальные вопросы совершенствования бухгалтерского 
учета. статистики и налогообложения: материалы VII международной научно-практической конференции. Тамбов, 2018. С. 170-177.

4. Рамазанова Е.С., Тимченко И.А. Формирование системы стратегических целей налоговой политики государства на региональном уровне // Актуальные вопросы совершенствования бухгалтерского учета. статистики и налогообложения: материалы VII международной научно-практической конференции. Тамбов, 2018. С. 266-273.

5. Адамова А.А., Загорулько В.В., Рыбалко С.С. Введение необлагаемого минимума при налогообложении физических лиц // Актуальные вопросы совершенствования бухгалтерского учета. Статистики и налогообложения: материалы VII международной научно-практической конференции. Тамбов, 2018. С. 65-74.

6. Баканова К.Д., Карнаухова Ю.Ю. Роль налоговой политики государства в социально-экономическом развитии регионов // Актуальные вопросы совершенствования бухгалтерского учета. статистики и налогообложения: материалы VII международной научно-практической конференции. Тамбов, 2018. С. 65-74.

7. Рощупкина В.В. Особенности современной государственной налоговой политики для предпринимателей в Российской Федерации // Финансы и кредит. 2019. Т. 25, № 6. С. 1373-1382.

8. Roshchupkina V.V. Methodical bases of rating assessment of tax policy efficiency // Advances in Economics, Business and Management Research. 2019. vol. 47. P. 211-214.

9. Чукунова И.В., Кальтымова С.А. Влияние изменений в государственной кадастровой оценке недвижимости на размер налога на имущество физических лиц [Электронный ресурс]. Режим доступа: https://elibrary.ru/item.asp?id=26197756.

10. Кошкина И.В. Кредитование начинающего предпринимателя // Финансы и кредит. 2017. Т. 23. № 30 (750). С. 1820-1830.

11. Хянненен В.Е. Конкретизация налогового законодательства органами местного самоуправления на примере установления налога на имущество физических лиц [Электронный ресурс]. Режим доступа: https://elibrary.ru/item.asp?id=24199704.

12. Мигашкина Е.С. Реформирование налога на имущество физических лиц и его влияние на доходы бюджета [Электронный ресурс]. Режим доступа: https://elibrary.ru/item.asp?id=25694288.

13. Дементьева Н.М., Дементьев Д.В. Налоговые каникулы для индивидуальных предпринимателей: ожидаемый результат // Финансы и кредит. 2015. №20 (644). С. 47-54.

14. Сиденко А.А. Налогообложение индивидуальных предпринимателей: постановка проблемы // Вестник научных конференций. 2016. №9-3 (13). С. 79-80.

15. Серов Е.В. Налогообложение имущества индивидуального предпринимателя // Новая наука: Современное состояние и пути развития. 2017. Т. 1. №3. С. 151-154.

16. Гаврисенко А.А. Налогообложение индивидуальных предпринимателей при сдаче в аренду недвижимого имущества // Современные наукоёмкие инновационные технологии: сборник статей Международной научно-практической конференции. 2019. С. 148-152.

17. Титова Д.А. Налогообложение индивидуальных предпринимателей в 2018 году // Молодой ученый. 2018. №36 (222). С. 43-45. 